\title{
Variations of $\mathrm{OH}$ rotational temperature over Syowa Station in the austral winter of 2008
}

\author{
Hidehiko Suzuki ${ }^{1}$, Yoshihiro Tomikawa ${ }^{1}$, Makoto Taguchi ${ }^{2}$, Takuji Nakamura ${ }^{1}$, and Masaki Tsutsumi ${ }^{1}$ \\ ${ }^{1}$ National Institute of Polar Research, 10-3, Midoricho, Tachikawa, Tokyo 190-8518, Japan \\ ${ }^{2}$ Rikkyo University, 3-34-1 Nishi-Ikebukuro, Toshima-ku, Tokyo 171-8501, Japan
}

(Received February 14, 2010; Revised July 6, 2010; Accepted July 15, 2010; Online published October 28, 2010)

\begin{abstract}
A grating spectrometer for hydroxyl $(\mathrm{OH})$ airglow installed at Syowa Station $\left(69^{\circ} \mathrm{S}, 39.6^{\circ} \mathrm{E}\right)$ by the 49th Japanese Antarctic Research Expedition (JARE49) has been in operation since late February, 2008. A dataset of 153 nights was acquired at this location in the austral winter season of 2008. This dataset shows variations in the rotational temperature over a range of temporal scales. The rotational temperature around the polar mesopause region is high in winter and decreases toward summer, which is a pattern similar to that observed at Davis Station, located at almost the same latitude as Syowa Station. A large temperature variation with a period of several days was observed in early May, 2008. Based on a comparison with a simultaneous dataset obtained by the SABER instrument onboard the TIMED satellite, it is inferred that this rotational temperature variation was due to the modulation of vertical motions around the mesopause.
\end{abstract}

Key words: Hydroxyl airglow, OH rotational temperature, Antarctic, Syowa Station, mesopause, ground-based observations.

\section{Introduction}

Hydroxyl $(\mathrm{OH})$ airglow is the brightest emission in the nightglow and was first reported by Meinel (1950). The spectral lines of vibration-rotation bands called the Meinel bands $\left(v^{\prime}<9\right)$ appear in the visible to infrared wavelengths. The mean altitude and thickness of the $\mathrm{OH}$ airglow layer have been measured to be 87 and $8 \mathrm{~km}$, respectively, by rocket-borne observations (Baker and Stair, 1988). A primary source of excited $\mathrm{OH}$ molecules at these altitudes is the reaction of atomic hydrogen with ozone (Bates and Nicolet, 1950).

$\mathrm{OH}$ airglow spectroscopy is a very reliable and useful method for determining the temperature of the upper mesosphere, and many optical observations have been made, particularly in the middle- and low-latitude regions (e.g., Krassovsky, 1972; Sivjee et al., 1972; Takahashi et al., 1974). In the northern polar region, Oznovich et al. (1995) used a Michelson interferometer to observe the $\mathrm{OH}$ (3-0) band and a scanning photometer to observed other airglow emissions (OI $557.7 \mathrm{~nm}$; sodium $589.3 \mathrm{~nm}$ ). Their aim was to investigate the behavior of atmospheric waves passing through these layers in Eureka, Canada $\left(80^{\circ} \mathrm{N}\right)$. Nielsen $e t$ al. (2002) reported a long-term variation in the $\mathrm{OH}$ rotational temperature using a 20 -year dataset obtained with an Ebert-Fastie scanning spectrometer at Longyearbyen, Norway $\left(78^{\circ} \mathrm{N}\right)$. Although $\mathrm{OH}$ airglow measurements have been made at only a limited number of Antarctic locations, but the data obtained in a number of these studies

Copyright (C) The Society of Geomagnetism and Earth, Planetary and Space Sciences (SGEPSS); The Seismological Society of Japan; The Volcanological Society of Japan; The Geodetic Society of Japan; The Japanese Society for Planetary Sciences; TERRAPUB.

doi:10.5047/eps.2010.07.010 provide important information. The first long-term observation of the $\mathrm{OH}$ rotational temperature that showed seasonal and interannual variations was a 7-year study using a Czerny-Turner scanning spectrometer at Davis Station (68.6 ${ }^{\circ}$ S) (Burns et al., 2002). French and Burns (2004) reported a 7-year trend in $\mathrm{OH}$ rotational temperature, identifying a long-term correlation between temperature and the solar cycle and effects of planetary wave penetration into the upper mesosphere during the winter season. Using the same $\mathrm{OH}$ rotational temperature dataset at Davis Station, French et al. (2005) reported an unusually high temperature for the austral winter of 2002 and found a 14-day oscillation with large amplitude $(\sim 15-20 \mathrm{~K})$ in early spring related to a planetary wave penetration into the mesopause region. Espy et al. (2003) also found a rapid and large-scale variation in $\mathrm{OH}$ rotational temperature which occurred simultaneously at Rothera Station $\left(68^{\circ} \mathrm{S}, 68^{\circ} \mathrm{W}\right)$ and Halley Station $\left(76^{\circ} \mathrm{S}\right.$, $27^{\circ} \mathrm{W}$ ). Since the meridional wind variation observed by a medium frequency (MF) radar at Rothera Station showed a very good correlation with the temperature variation during this period, these researchers concluded that the temperature variation was caused by an enhancement of the interhemispheric meridional flow from summer (north) to winter hemisphere (south). At a higher latitude, Azeem and Sivjee (2009) reported tidal features of $\mathrm{OH}$ rotational temperature at the South Pole using dataset of OH (3-1) band observations over the period between 1994 and 2007.

Recent global observations by satellites have revealed detailed characteristics of $\mathrm{OH}$ airglow. These have resulted in the construction of an exact empirical model of the height profile of $\mathrm{OH}$ emission based on 6 years of measurements by the Wind Imaging Interferometer (WINDII) onboard the UARS satellite (Liu and Shepherd, 2006). WINDII mea- 
sures volume emission rate profiles of the $\mathrm{OH}(8-3)$ band $\mathrm{P}_{1}$ (3) line airglow $(734 \mathrm{~nm})$. Liu and Shepherd (2006) used 50,000 profiles of volume emission rate obtained within latitudes of $\pm 40^{\circ}$ over the period from November 1991 to August 1997 and found universality of the inverse correlation between peak altitude and the integrated emission rate.

The inverse relationship between altitude and the intensity of $\mathrm{OH}$ airglow peak has also been verified by the Sounding of the Atmosphere by Broadband Emission Radiometry (SABER) instruments onboard the Thermosphere Ionosphere Mesosphere Energetics and Dynamics (TIMED) satellite in the polar region (see Russell et al., 1999). Winick et al. (2009) demonstrated a relationship between $\mathrm{OH}$ layer height and volume emission rate at the peak altitude at night in the latitude region between $60^{\circ} \mathrm{S}$ and $80^{\circ} \mathrm{N}$ during the period from February to March of 2004, 2005, and 2006. According to their results, the northern high-latitude region was under an unusual condition in the boreal winters of 2004 and 2006, namely, an extremely low $\mathrm{OH}$ peak altitude that sometimes descended down to $80 \mathrm{~km}$. This is thought to be related to a major stratospheric warming event. The inverse relationship is still maintained even in such extreme cases. Most of these variations in $\mathrm{OH}$ rotational temperature and integrated intensity are consistent with vertical motions which cause modulations of the OH peak altitude (Ward, 1999).

The results of these earlier studies using a nearly global dataset provided by satellite measurements has enabled great advances to be made in our understanding of $\mathrm{OH}$ airglow features. It is now known that most variations in the intensity and rotational temperature of $\mathrm{OH}$ airglow are caused by modulation of the $\mathrm{OH}$ layer by a vertical motion induced by atmospheric waves or circulations. Even with such knowledge of $\mathrm{OH}$ airglow, however, ground-based observations are still considered to be an important method by which to monitor not only the mesopause temperature but also local phenomena in the upper mesosphere. Groundbased $\mathrm{OH}$ airglow observations are particularly useful in the Antarctic where few such observations have been performed in the past.

In order to monitor the polar mesopause temperature, a grating spectrometer for $\mathrm{OH}$ airglow was installed at Syowa Station $\left(69^{\circ} \mathrm{S}, 39.6^{\circ} \mathrm{E}\right)$ by the 49 th Japanese Antarctic Research Expedition (JARE49) in early 2008. Here we report the first results of the $\mathrm{OH}$ rotational temperature observation over Syowa Station in the winter of 2008.

\section{Instrumentation}

The Syowa Station spectrometer consists of a fast optical system, a transmission grating as the dispersion optics, and a high-sensitivity CCD camera. The operating spectral region just covers the $\mathrm{OH}(8-4)$ band (900-990 nm), with a moderate spectral resolution of $0.27 \mathrm{~nm}$. A backilluminated CCD with an infrared-enhanced quantum efficiency is used as the imaging device. The sensitivity and spectral resolution of the spectrometer were calibrated at the optical calibration facility of the National Institute of Polar Research, Japan. The instrument was installed in the optical building at Syowa Station in February 2008 by JARE49. The narrow instrumental field-of-view, $4.5^{\circ}$
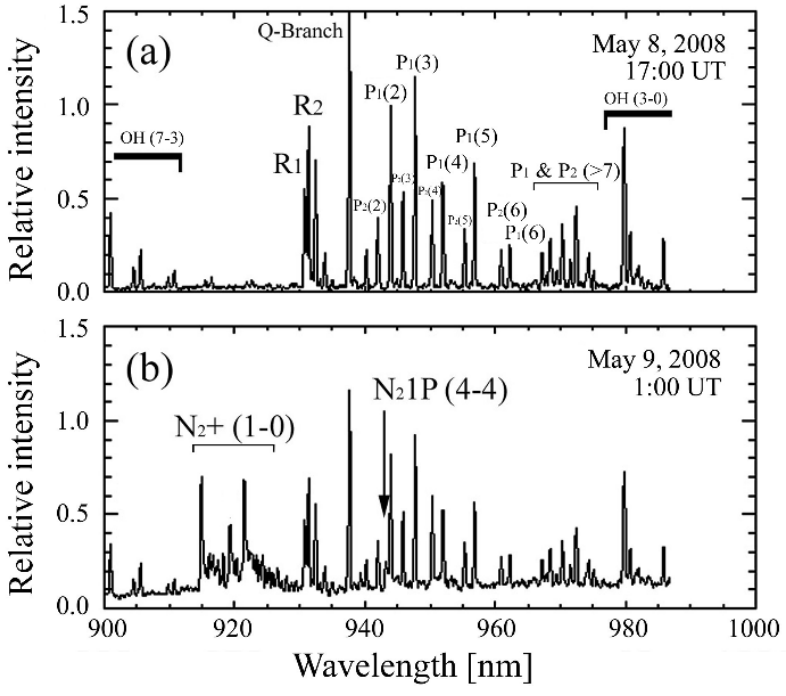

Fig. 1. Sample spectra of the $\mathrm{OH} 8-4$ band obtained with a 1-min exposure in (a) quiet and (b) active auroral conditions.

in a direction perpendicular to the magnetic meridian and $0.001^{\circ}$ along the magnetic meridian, is fixed at the local magnetic zenith. Nominal exposure time is $1 \mathrm{~min}$. The full width at half-maximum (FWHM) of the instrumental function is $0.23 \mathrm{~nm}$. Since the spectral intervals of the rotational lines in the $\mathrm{OH}(8-4)$ band are larger than $1.7 \mathrm{~nm}$, the resolution is sufficient to resolve these lines. However, this resolution is not sufficient to resolve $\Lambda$-splitting effects for each rotational line. Sample spectra of the $\mathrm{OH}(8-4)$ band obtained under quiet and active auroral conditions are shown in Fig. 1. A remarkable difference between the upper and lower spectra is the presence of the $\mathrm{N}_{2}^{+}$Meinel (1-0) band emissions near $920 \mathrm{~nm}$ and that of the $\mathrm{N}_{2}$ 1PG (4-4) band emissions near $944 \mathrm{~nm}$ from the aurora. The $\mathrm{N}_{2}^{+}$ Meinel (1-0) emission is useful as a measure of auroral activity. The $\mathrm{N}_{2}$ 1PG (4-4) band emission partially overlaps a rotational line of the $\mathrm{OH}(8-4)$ band. The intensities of rotational lines $\mathrm{P}_{1}(2), \mathrm{P}_{1}(3)$, and $\mathrm{P}_{1}(5)$ are used to derive the rotational temperature. The rotational line $\mathrm{P}_{1}(4)$ is not used for temperature derivation because there is a strong water vapor absorption line near it. The intensity ratio between two rotational lines can be converted to the rotational temperature, which is equivalent to the atmospheric temperature, by assuming a local thermal equilibrium. In this study, two pairs of rotational lines, namely, $\mathrm{P}_{1}(2) / \mathrm{P}_{1}(5)$ and $\mathrm{P}_{1}(3) / \mathrm{P}_{1}(5)$, were used to calculate rotational temperature because they are the most sensitive to the fluctuations in rotational temperature. Further details of the method used to derive rotational temperature are described in Suzuki et al. (2009).

Since this spectrometer was originally designed to observe the behavior of $\mathrm{OH}$ rotational temperature during an active aurora event, the $\mathrm{OH}(8-4)$ band with relatively less contamination from strong aurora emissions is selected. However, it should be noted that a weak auroral emission by $\mathrm{N}_{2}$ 1PG overlaps the $\mathrm{OH}$ band. This auroral emission may cause contamination of the rotational temperature measurement. Consequently, two rotational temperatures were de- 


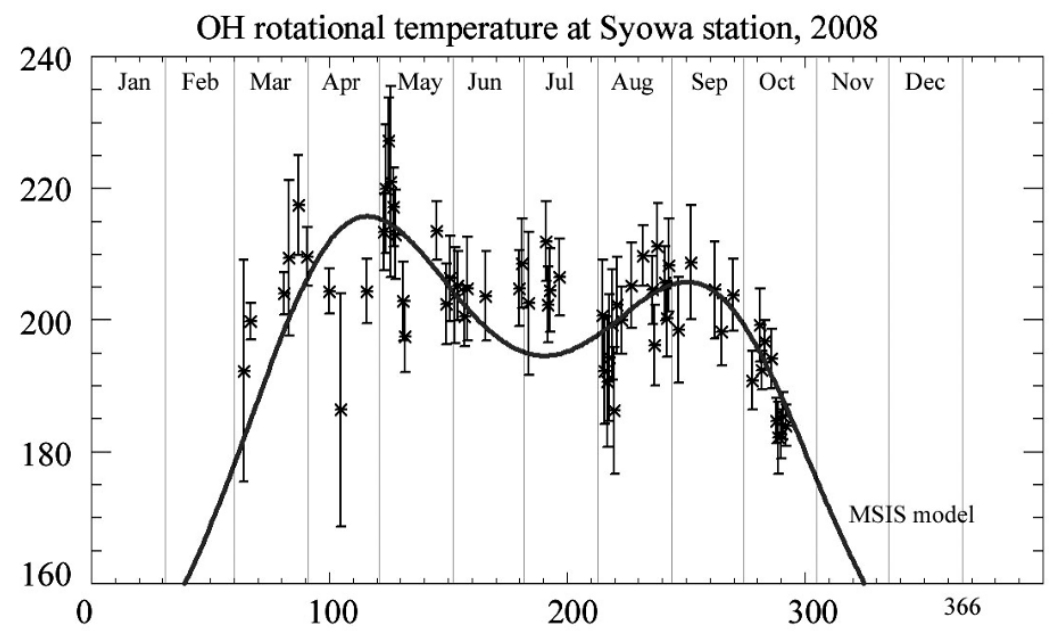

Fig. 2. Seasonal variations in the daily mean $\mathrm{OH}$ rotational temperature (asterisks) over Syowa Station in 2008 and $\mathrm{MSISE}-90$ temperature at $70^{\circ} \mathrm{S}$ (thick solid line). Error bars represent standard deviations of the rotational temperature during a 1-day period.

rived from two pairs of rotational lines, i.e. $\mathrm{P}_{1}(2) / \mathrm{P}_{1}(5)$ and $\mathrm{P}_{1}(3) / \mathrm{P}_{1}(5)$, to remove data affected by auroral contamination. If their difference is larger than $10 \mathrm{~K}$, the temperatures are omitted as inaccurate values due to auroral contamination. The relationship between auroral activity and the behavior of OH airglow is reported in Suzuki et al. (2010).

In this study, we used a dataset from the SABER instrument onboard the TIMED satellite to examine the causes of the ground observed variations. SABER is a ten-channel radiometer providing near-global measurements of the emissions from several sources. Two of these channels are designed to observe the emission from $\mathrm{OH}$ airglow. These channels measure the 2.0- and $1.6-\mu \mathrm{m}$ radiation from the pair of $\mathrm{OH}(9-7)$ and $\mathrm{OH}(8-6)$ and the pair of $\mathrm{OH}(5-3)$ and OH (4-0) bands, respectively (Russell et al., 1999). Vertical profiles of the volume emission rate from $\mathrm{OH}$ airglow can be derived from these datasets. The other channels obtain near infrared to infrared radiation from $\mathrm{CO}_{2}$, and these are used to retrieve atmospheric temperature and pressure up to an altitude of approximately $120 \mathrm{~km}$. The orbit of the TIMED satellite has a 60-day yaw cycle, switching between the northern hemisphere viewing mode $\left(83^{\circ} \mathrm{N}-52^{\circ} \mathrm{S}\right)$ and southern hemisphere viewing mode $\left(52^{\circ} \mathrm{N}-83^{\circ} \mathrm{S}\right)$ every 60 days.

\section{Observations}

Observations were made between 29 February and 18 October 2008. This period corresponds to the period from early autumn to late spring, when the dark night occurs. The observation time of each night was determined by the solar zenith angle. In principle, the observations were conducted when the solar elevation angle was $<18^{\circ}$ below the horizon (astronomical twilight). The exposure time was set to $1 \mathrm{~min}$ throughout the entire 2008 season. The observations were conducted over 158 nights, including cloudy nights, with the exception of nights when weather conditions were extremely severe, such as heavy snow or blizzards. Of the observed nights, 59 were perfectly clear, 57 were partly clear, and the others were completely cloudy. Although clouds degrade a signal-to-noise ratio due to extinction- and hence the precision of the temperature measurement may decrease-the observation itself is not impossible. However, moonlight scattered by clouds contaminates the observed spectrum and can cause a bias in the temperature measurement due to a complex absorption spectrum in the water in the clouds. Therefore, we did not use the datasets obtained only cloudy night under the moonlight in the data analysis.

The seasonal variation in the daily averaged $\mathrm{OH}$ rotational temperature on clear days over Syowa Station in 2008 is shown in Fig. 2. The error bars show the standard deviations of the temperature variation each night. The solid line over-plotted together with the $\mathrm{OH}$ temperature is the atmospheric temperature at the typical $\mathrm{OH}$ layer height, $87 \mathrm{~km}$, over Syowa Station that was obtained from the atmospheric empirical Mass-Spectrometer, Incoherent-Scatter Extended (MSISE-90) model. The details of this model are described in Hedin (1991). The MSISE-90 temperature is roughly within the error bars of the observed rotational temperature. Large deviations in the observed temperature from the model temperature are observed around the midwinter period. These are thought to be caused by the seasonal variation in the model temperature around the mesopause being composed of the empirical fit involving only annual and semi-annual terms (Burns et al., 2002). The seasonal variation shown in Fig. 2 is usually thought to be the result of the meridional circulation induced by gravity waves through momentum deposition (Lindzen, 1981). The meridional circulation around the mesopause consists of meridional flow from the summer to winter hemispheres and from ascent and descent in the summer and winter hemispheres, respectively. An upward motion causes adiabatic cooling around the polar summer mesopause region, while a downward motion causes adiabatic heating around the polar winter mesopause region. The seasonal variation in rotational temperature, which is high in winter and low in summer, is a typical variation at the polar mesopause height (90$100 \mathrm{~km}$ ). This seasonal variation is similar to that obtained by the 7-year $\mathrm{OH}$ rotational temperature observational study (1990 and 1995-2000) at Davis Station $\left(69^{\circ} \mathrm{S}\right.$, 


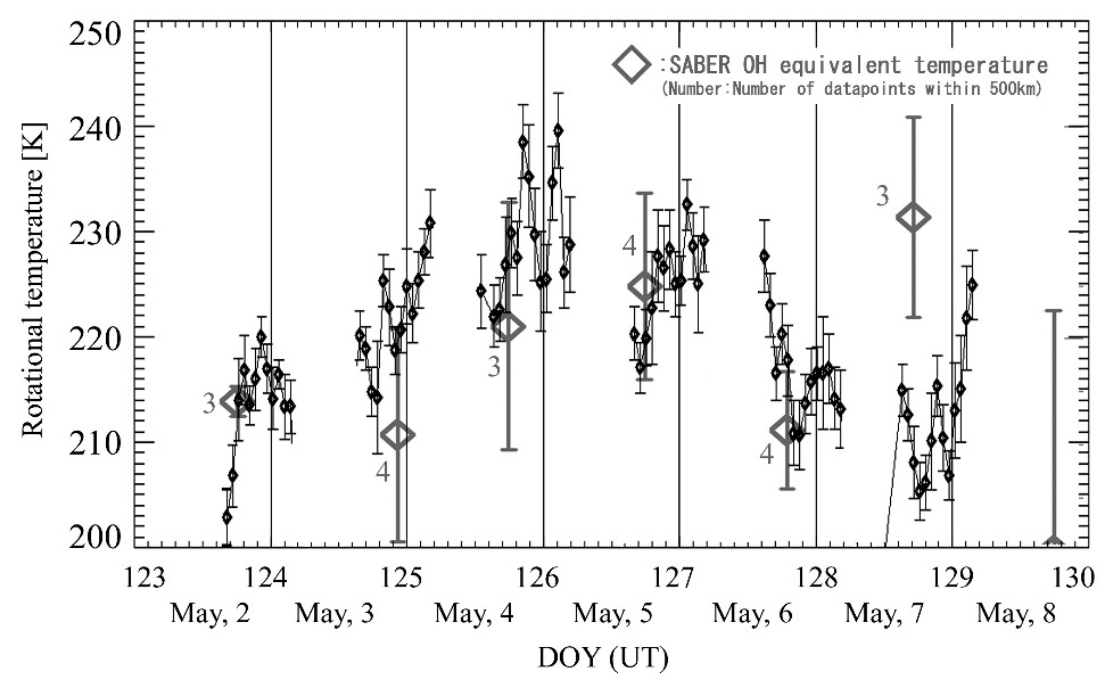

Fig. 3. Hourly averaged rotational temperature (small diamonds) and $\mathrm{OH}$ equivalent temperature (large diamonds) derived from SABER data during DOY 123-130. Error bars represent standard deviations of rotational temperature during a 1-h period.

$78^{\circ} \mathrm{E}$ ), Antarctica (Burns et al., 2002).

As shown in Fig. 2, a large enhancement in the $\mathrm{OH}$ rotational temperature was observed in early May 2008. The hourly averaged rotational temperature during DOY $123-$ 130 is shown in Fig. 3. The error bars show the standard deviations of the temperature variations within the corresponding hour. The weather conditions between 2 and 8 May were very good, with no moonlight. Thus, continuous observation, except for the daytime, was successfully conducted. The $\mathrm{OH}$ rotational temperature shown in Fig. 3 exhibits fluctuations with a period varying from several hours to several days. The temperature variations with a period of several hours are thought to be due to gravity waves in the $\mathrm{OH}$ airglow layer. In this paper, we focus on a large temperature variation with a period of several days during DOY 123 to 130 . The rotational temperature increases from 210 $220 \mathrm{~K}$ on DOY $123 / 124$ to about $235 \mathrm{~K}$ on DOY $125 / 126$, and then decreases down to about $210 \mathrm{~K}$ on DOY 128/129.

For comparison, the $\mathrm{OH}$ equivalent temperature, which is the atmospheric temperature weighted by the vertical profile of $\mathrm{OH}$ volume emission rate obtained by the SABER observations, is plotted in Fig. 3 (diamonds). Each value of $\mathrm{OH}$ equivalent temperature is given as a mean of typically three or four tangential points within a 500-km distance of Syowa Station. Since SABER passes closely over Syowa Station twice a day in its ascending and descending orbit, the universal time (UT) of these data points is also derived by averaging. The typical sampling times above Syowa Station in this period are 13-14 UT and 22-23 UT for ascending and descending orbits, respectively. The mean distance of these data points from Syowa Station is about $200 \mathrm{~km}$. The numbers located near the diamond symbols specify the number of SABER profiles used to calculate the daily average value and UT. The process used to derive $\mathrm{OH}$ equivalent temperature and the altitude profiles of atmospheric temperature and $\mathrm{OH}$ volume emission rates is as follows. First, the averaged profiles of temperature and $\mathrm{OH}$ volume emission rates are calculated by an equal weighting of three to four soundings. Then, two profiles of $\mathrm{OH}$ volume emission rate of two SABER channels are normalized with integrated emission rates through the $\mathrm{OH}$ layer. The two SABER OH VER channels are at $1.6 \mu \mathrm{m}$, which mostly includes the $\mathrm{OH}(4-2)$ and $\mathrm{OH}(5-3)$ bands, and $2.0 \mu \mathrm{m}$, which mostly includes the $\mathrm{OH}(8-6)$ and $\mathrm{OH}(9-7)$ bands. These two altitude profiles are combined and averaged to obtain the weighting function. Finally, these weighting functions are combined with the altitude profiles of temperature to obtain $\mathrm{OH}$ equivalent temperatures. Good agreement between the $\mathrm{OH}$ rotational and equivalent temperatures is seen except on DOY 128. A possible reason for this difference is the effect of unknown local heating or a horizontal inhomogeneity of temperature because the field of view of SABER is not necessarily the same as that of the ground-based observation.

\section{Discussion}

There are two possible mechanisms to explain the large increase in rotational temperature in early May. One is an increase in atmospheric temperature within the $\mathrm{OH}$ layer and another is a change in the height of the layer. SABER profiles of the $\mathrm{OH}$ airglow volume emission rate (upper panel) and atmospheric temperature (lower panel) during DOY 120 to 130 are shown in Fig. 4 to identify the source of the large temperature variation. The $\mathrm{OH}$ peak altitude gradually descended from DOY 120 to reach the bottom height of $82-83 \mathrm{~km}$ on DOY 125 and then returned to the original height of approximately $86 \mathrm{~km}$ a few days later.

If the change in the peak position of the $\mathrm{OH}$ airglow layer without downward motion is responsible for the large temperature change during DOY 124-129, the vertical gradient of the background temperature should be $-7 \mathrm{~K} / \mathrm{km}$. However, no such vertical gradients of temperature are seen in the SABER temperature profiles shown in the lower panel of Fig. 4. Furthermore, most of these profiles show positive vertical temperature gradients during this period.

The $\mathrm{OH}$ equivalent temperature obtained by the SABER observation was found to be in good agreement with the $\mathrm{OH}$ rotational temperature obtained by the ground-based 
SABER OH profile $(\mathrm{OH} 16 \& \mathrm{OH} 20)$ and temperature . Tangent points $<500 \mathrm{~km}$ from SYOWA

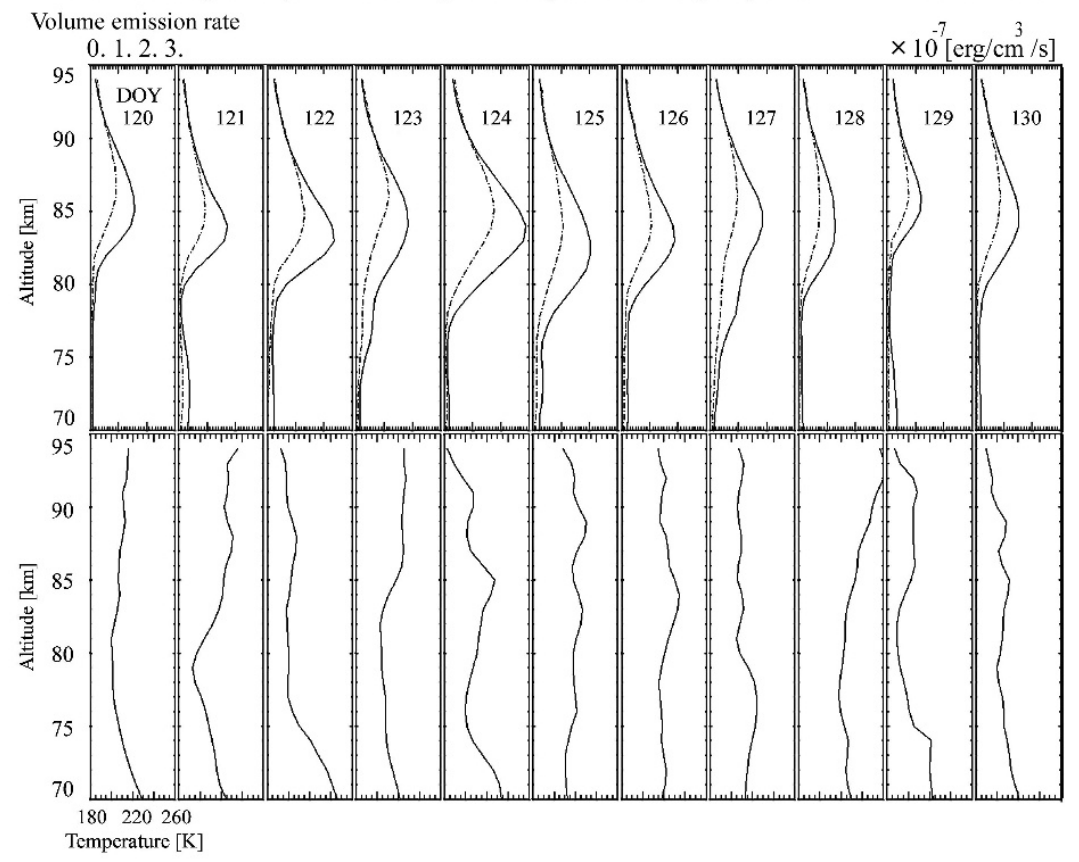

Fig. 4. SABER profiles of the $\mathrm{OH}$ airglow volume emission rate $\left[\mathrm{erg} / \mathrm{m}^{3} / \mathrm{s}\right]$ (upper panel) and atmospheric temperature [K] (lower panel) during DOY 120-130. Solid and dotted lines in the upper panel represent the $\mathrm{OH}$ volume emission rates corresponding to 1.6- and 2.0- $\mu \mathrm{m}$ channels, respectively.

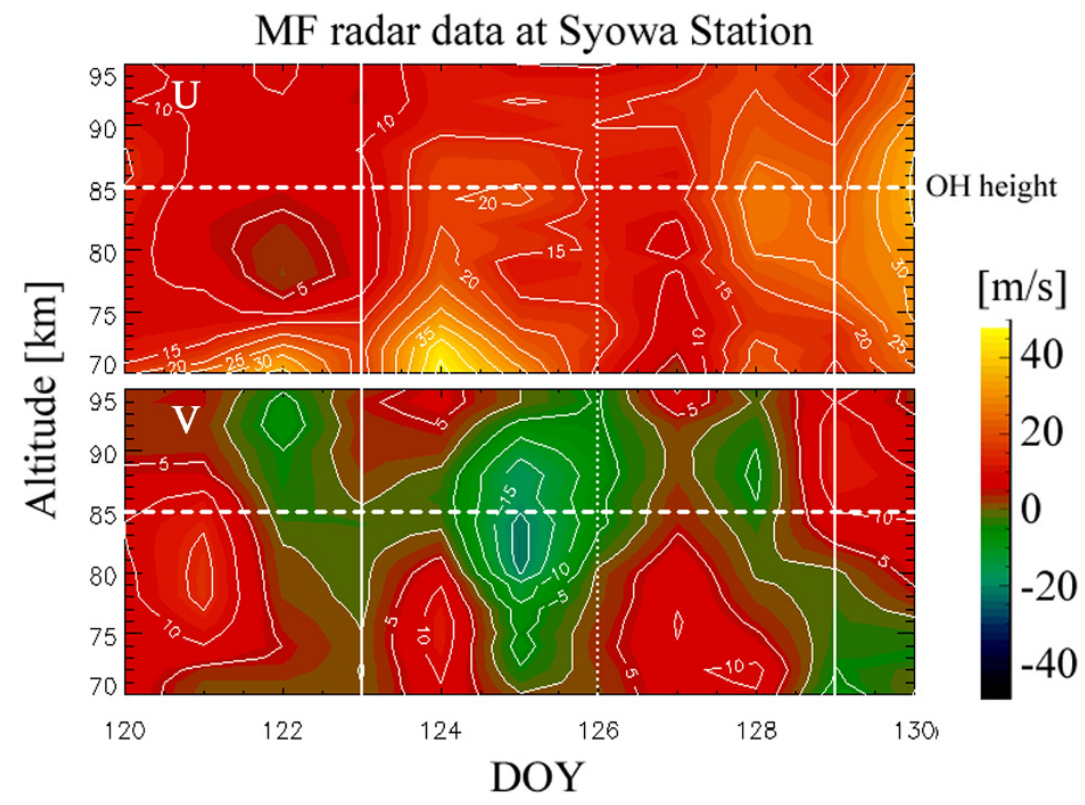

Fig. 5. Time-height sections of daily mean (top) zonal and (bottom) meridional winds between DOY 120 and 130 obtained by the MF radar observation at Syowa Station. Contour intervals are $5 \mathrm{~m} / \mathrm{s}$. White solid lines represent the period of the $\mathrm{OH}$ airglow observation. White dotted lines represent the day of $\mathrm{OH}$ rotational temperature maximum.

observation, indicating that the large increase in $\mathrm{OH}$ rotational temperature occurred simultaneously with the descent of the $\mathrm{OH}$ layer. An enhanced downward motion in the $\mathrm{OH}$ layer causes adiabatic heating and moves the $\mathrm{OH}$ layer downward. Therefore, the large temperature variation observed in early May 2008 over Syowa Station is thought to be due to the enhancement of the downward motion and the resulting adiabatic heating.

Daily mean horizontal winds during periods between
DOY 120 and 130 obtained by the MF radar observation at Syowa Station are shown in Fig. 5 in order to determine the cause of the enhanced vertical motion. Details about MF radar in Syowa Station are described in Tsutsumi et al. (2001). The data are daily averaged to remove diurnal and semi-diurnal tide components. The enhanced poleward (southward) wind is shown around the $\mathrm{OH}$ peak altitude on DOY 125, which corresponds to the maximum of $\mathrm{OH}$ rotational temperature shown in Fig. 3. Thus, this enhanced 
poleward motion around the $\mathrm{OH}$ peak altitude is thought to be related to the enhanced downward motion that caused the increase in the rotational temperature. Since there are no remarkable zonal phase structures in the SABER temperature data during this period (not shown here), it is difficult to infer that this local poleward wind disturbance is due to any modulation of planetary waves or enhanced meridional circulation. However, it is worth noting that the enhanced poleward wind on DOY 125 covers the whole height range of the $\mathrm{OH}$ layer. The relationship between meridional flow and $\mathrm{OH}$ temperature is quantitatively similar to the results of Espy et al. (2003). These researchers concluded that the temperature variation was caused by an enhancement of the inter-hemispheric meridional flow from the summer (north) to winter hemisphere (south) based on the very good correlation between temperature and meridional wind at the mesopause height.

The enhanced vertical wind during the temperature increase can be quantitatively estimated by the following simple equations. Since the temperature variation before this event is small (not shown), it is assumed that the temperature and winds are steady until the temperature variation starts. Taking the temperature profile and constant vertical wind before the vertical wind enhancement to be $T_{0}(z)$ and $w_{0}$, respectively, the equation of thermodynamics for balanced initial condition is represented as:

$$
w_{0}\left(\frac{\partial T_{0}}{\partial z}+\frac{g}{c_{p}}\right)=-\frac{T_{0}-T_{\mathrm{rad}}}{\tau},
$$

where $g$ is gravitational acceleration, $c_{p}$ is a specific heat at constant pressure, $T_{\text {rad }}$ is the radiative equilibrium temperature, and $\tau$ is the time constant of radiative relaxation. This equation represents a steady-state equilibrium between the constant background vertical wind and the radiative cooling. After the vertical wind and temperature are changed to $w_{0}+w^{\prime}$ and $T_{0}+T^{\prime}(t)$, respectively, the equation of thermodynamics is represented as:

$$
\frac{\partial T^{\prime}}{\partial t}=-\left(w_{0}+w^{\prime}\right)\left(\frac{\partial T_{0}}{\partial z}+\frac{g}{c_{p}}\right)-\frac{\left(T_{0}+T^{\prime}\right)-T_{\mathrm{rad}}}{\tau}
$$

where $\partial T^{\prime} / \partial z=0$ and $\nabla_{H} T_{0}=0$ are assumed due to following reasons. As described above, the downward motion is thought to be large scale in this case. Since the quasi geostrophic approximation can be applied to the large-scale flow in the extratropics, the temperature advection associated with the horizontal gradient of background temperature is thought to be negligibly small compared to that due to the vertical gradient of the background temperature. In addition, the variation in temperature, $T^{\prime}$, is thought to be independent of height to a good approximation so the $\partial T^{\prime} / \partial z$ term can also be neglected. Although the enhanced vertical wind can change the vertical mixing ratio profiles of various chemical species and radiative efficiency, such effects are not considered here because an enhanced vertical downwelling estimated from the $\mathrm{OH}$ layer lowering shown in Fig. 4 is only approximately $1-2 \mathrm{~km} /$ day. Such a small displacement would not cause a drastic change in the distributions of chemical species such as $\mathrm{O}_{3}$ and $\mathrm{H}$, which are the primary sources of an exothermic chemical reaction in the mesopause height (Mlynczak and Solomon, 1993). From these two equations, the relationship between $w^{\prime}$ and $T^{\prime}$ can be given as:

$$
w^{\prime}=-\left(\frac{\partial T^{\prime}}{\partial t}+\frac{T^{\prime}}{\tau}\right) /\left(\frac{\partial T_{0}}{\partial z}+\frac{g}{c_{p}}\right) .
$$

For the observed case, $\partial T^{\prime} / \partial t$ is about $20 \mathrm{~K} / 2$ days. A typical value for $\tau$ is about 5 days (Wehrbein and Leovy, 1982), $T^{\prime}=20 \mathrm{~K}$, and $g / c_{p}$ is approximately $9.7 \times 10^{-5} \mathrm{~K} / \mathrm{cm}$. In principle, the gradient of background temperature, $\partial T_{0} / \partial z$, can be derived from the SABER temperature profile. However, the available SABER observations are nearly fixed in local time and drastically variable with height around the mesopause, such that a reliable value of the vertical gradient of background temperature cannot be obtained. Therefore the value estimated from the MSISE-90 model (Hedin, 1991), $\partial T_{0} / \partial z=-1.5 \mathrm{~K} / \mathrm{km}\left(=-1.5 \times 10^{-5} \mathrm{~K} / \mathrm{cm}\right)$ at the height of $85 \mathrm{~km}$ is adopted in this estimation. Using these values and the assumptions, enhancement of vertical wind is estimated to be $1.5 \mathrm{~km} /$ day. The typical value of downward wind in the spring season is $0.5-1.0 \mathrm{~km} / \mathrm{day}$ at the mesopause height in Antarctica (Dunkerton, 1978; Xun et al., 2001). Thus, the increase of temperature observed in early May is achieved by an enhancement of the downward wind with a magnitude twofold larger than the usual condition, if it is caused by the adiabatic heating.

\section{Summary and Conclusions}

A grating spectrometer for $\mathrm{OH}$ airglow was installed at Syowa Station $\left(69^{\circ} \mathrm{S}, 39.6^{\circ} \mathrm{E}\right)$ by JARE49 in early 2008 to monitor the polar mesopause temperature. The observations were performed during 158 nights. Of the observed nights, 59 were perfectly clear in the austral winter of 2008 . The dataset shows a range of variations over both short and long time scales.

The rotational temperature increases from the autumn to the winter, and then decreases toward the spring. This feature is consistent with those observed previously in the polar mesopause region (e.g. Burns et al., 2002) and obtained from the MSISE-90 model.

In addition to the seasonal variation, large day-to-day variability in rotational temperature was observed. The rotational temperature showed a $20-\mathrm{K}$ increase during 2 days in early May 2008. Based on a comparison of $\mathrm{OH}$ volume emission rate and temperature profiles observed by the SABER instruments onboard the TIMED satellite, it is inferred that the temperature increase was induced by the enhancement of the downward motion followed by the lowering of the $\mathrm{OH}$ airglow layer over Syowa Station. A simple quantitative discussion to estimate the enhanced vertical wind during the temperature increase demonstrated that a downward motion twofold larger than the typical vertical wind can cause the observed increase in temperature at the height of the $\mathrm{OH}$ layer. However, the cause of the enhanced downward motion can not be clarified by the single MF radar observation.

Although it was not referred to in this paper, there is a significant reduction in rotational temperature during early August, as shown in Fig. 2. In this period, the upwelling of the $\mathrm{OH}$ layer height is also found in the SABER dataset 
(not shown). However, no remarkable enhancement of the equatorward wind is seen in the MF dataset for this period. A similar depletion has also been reported in other winters at Davis Station, which is located at a distance $+39^{\circ}$ in longitude from Syowa Station at nearly the same latitude (French et al., 2005). The observations of these researchers show nearly regular reductions in the $\mathrm{OH}$ temperature during middle August in each winter. We suggest that this is an interesting phenomenon and consider that the cause of this "August depletion" may not be the same as that described herein. This depletion will be analyzed and discussed in future work.

Additional interesting scientific issues, such as the nature of the long-term trend in upper mesospheric temperatures and auroral effects on the polar mesopause region, will be investigated in the future using the long-term data set produced by this instrument.

Acknowledgments. The authors are grateful to the SABER team of the NASA/TIMED mission for providing the temperature and $\mathrm{OH}$ emission dataset (Ver. 1.07).

\section{References}

Azeem, S. M. I. and G. G. Sivjee, Multiyear observations of tidal oscillations in $\mathrm{OH} \mathrm{M}(3,1)$ rotational temperatures at South Pole, Antarctica, $J$. Geophys. Res., 114, A06312, doi:10.1029/2008JA013976, 2009.

Baker, D. J. and A. T. Stair Jr., Rocket measurements of the altitude distribution of the hydroxyl emission, Phys. Scr., 37, 611-622, 1988.

Bates, D. R. and M. Nicolet, The photochemistry of atmospheric water vapor, J. Geophys. Res., 55, 301-327, 1950.

Burns, G. B., W. J. R. French, P. A. Greet, F. A. Phillips, P. F. B. Williams, K. Finlayson, and G. Klich, Seasonal variations and inter-year trends in seven years of hydroxyl airglow rotational temperatures at Davis station (69S, 78E), Antarctica, J. Atmos. Sol. Terr. Phys., 64, 1167-1174, 2002.

Dunkerton, T., On the mean meridional mass motions of the stratosphere and mesosphere, J. Atmos. Sci., 35(12), 2325-2333, 1978.

Espy, P. J., R. E. Hibbins, G. O. L. Jones, D. M. Riggin, and D. C. Fritts, Rapid, large-scale temperature changes in the polar mesosphere and their relationship to meridional flows, Geophys. Res. Lett., 30(5), 1240, doi:10.1029/2002GL016452, 2003.

French, W. J. R. and G. B. Burns, The influence of large-scale oscillations on long-term trend assessment in hydroxyl temperatures over Davis, Antarctica, J. Atmos. Sol.-Terr. Phys., 66, 493-506, 2004.

French, W. J. R., G. B. Burns, and P. J. Espy, Anoumalous winter hydroxyl temperatures at $69^{\circ} \mathrm{S}$ during 2002 in a multiyear context, Geophys. Res. Lett., 32, L12818, doi:10.1029/2004GL022287, 2005.

Hedin, A. E., Extension of the MSIS Thermospheric Model into the Middle and Lower Atmosphere, J. Geophys. Res., 96, 1159-1172, 1991.
Krassovsky, V. I., Infrasonic variations of $\mathrm{OH}$ emission in the upper atmosphere, Ann. Geophys., 28, 739-746, 1972.

Lindzen, R. S., Turbulence and stress owing to gravity wave and tidal breakdown, J. Geophys. Res., 86, 9707-9714, 1981.

Liu, G. and G. G. Shepherd, An empirical model for the altitude of the $\mathrm{OH}$ nightglow emission, Geophys. Res. Lett., 33, L09805, doi:10.1029/2005GL025297, 2006.

Meinel, A. B., OH emission bands in the spectrum of the night sky, Astrophys. J., 111, 555-564, 1950.

Mlynczak, M. G. and S. Solomon, A detailed evaluation of the heating efficiency in the middle atmosphere, J. Geophys. Res., 98(D6), 10,51710,541, 1993.

Nielsen, K. P., F. Sigernes, E. Raustein, and C. S. Deehr, The 20-year change of the Svalbard OH-temperatures, Phys. Chem. Earth, 27, 555561, 2002.

Oznovich, I., D. J. McEwen, and G. G. Sivjee, Temperature and airglow brightness oscillations in the polar mesosphere and lower thermosphere, Planet. Space Sci., 43, 1121-1130, 1995.

Russell, J. M. III, M. G. Mlynczak, L. L. Gordley, J. Tansock, and R. Esplin, An over view of the SABER experiments and preliminary calibration results, Proc. SPIE, 3756, 277-288, 1999.

Sivjee, G. G., K. K. Dick, and P. D. Feldman, Temporal variations in nighttime hydroxyl rotational temperature, Planet. Space Sci., 20, 261-269, 1972.

Suzuki, H., M. Taguchi, Y. Kanai, and N. Takeyama, Fast spectrometer for ground-based observations of $\mathrm{OH}$ rotational temperature, Appl. Opt., 48(6), 1119-1127, 2009.

Suzuki, H., M. Tsutsumi, T. Nakamura, and M. Taguchi, The increase in $\mathrm{OH}$ rotational temperature during an active aurora event, Ann. Geophys., 28, 705-710, 2010.

Takahashi, H., B. R, Clemesha, and Y. Sahai, Nightglow $\mathrm{OH}(8,3)$ band intensities and rotational temperature at $23^{\circ} \mathrm{S}$, Planet. Space Sci., 22, 1323-1329, 1974.

Tsutsumi, M., T. Aso, and M. Ejiri, Initial results of Syowa MF radar observations in Antarctica, Adv. Polar Upper Atmos. Res., 15, 103-116, 2001.

Ward, W. E., A simple model of diurnal variations in the mesospheric oxygen nightglow, Geophys. Res. Lett., 26, 3565-3568, 1999.

Wehrbein, W. M. and C. B. Leovy, An accurate radiative heating and cooling algorithm for use of dynamical model of middle atmosphere, J. Atmos. Sci., 39, 1532-1544, 1982.

Winick, J. R., P. P. Wintersteiner, R. H. Picard, D. Esplin, M. G. Mlynczak, J. M. Russell, and L. L. Gordley, $\mathrm{OH}$ layer characteristics during unusual boreal winters of 2004 and 2006, J. Geophys. Res, 114, A02303, doi:10.1029/2008JA013688, 2009.

Xun, Z., J. Yee, and E. R. Talaat, Diagnosis of dynamics and energy balance in the mesosphere and lower thermosphere, J. Atmos. Sci., 58, 2441-2454, 2001.

H. Suzuki (e-mail: hsuzuki@nipr.ac.jp), Y. Tomikawa, M. Taguchi, T. Nakamura, and M. Tsutsumi 